Investigating the mediating role of organizational trust in the relationship between perceived organizational support and Knowledge sharing

Karim Shateri

Islamic Azad University, Abdanan, Iran

Ali Asghar Hayat

Shiraz University of Medical Sciences, Shiraz, Iran

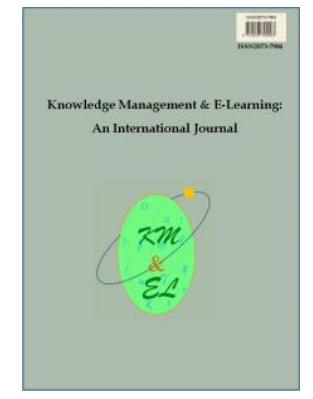

Knowledge Management \& E-Learning: An International Journal (KM\&EL) ISSN 2073-7904

Recommended citation:

Shateri, K., \& Hayat, A. A. (2020). Investigating the mediating role of organizational trust in the relationship between perceived organizational support and Knowledge sharing. Knowledge Management \& E-Learning, 12(3), 298-314. https://doi.org/10.34105/j.kmel.2020.12.016 


\title{
Investigating the mediating role of organizational trust in the relationship between perceived organizational support and Knowledge sharing
}

\author{
Karim Shateri* \\ Department of Primary Education, Abdanan Center \\ Islamic Azad University, Abdanan, Iran \\ E-mail: shatery20@gmail.com
}

\author{
Ali Asghar Hayat* \\ Clinical Education Research Center \\ Shiraz University of Medical Sciences, Shiraz, Iran \\ E-mail: ali.hayat63@gmail.com
}

*Corresponding author

\begin{abstract}
Knowledge sharing is vital for any organization, and it has an essential impact on developing skills, increasing value, and maintaining a competitive advantage in the organization. In the knowledge management (KM) literature, perceived organizational support and organizational trust have been pointed out as primary factors for knowledge sharing. The present study investigated the role of perceived organizational support in promoting nurses' knowledge sharing, considering organizational trust as a mediator. The crosssectional study design was applied to examine the hypothesized relationships. Data were collected using three questionnaires from three hundred thirty nurses working in five public hospitals in Shiraz city. The Partial Least Squares Structural Equation Modeling (PLS-SEM) approach was used to analyze data. The results revealed a significant and positive association between perceived organizational support, organizational trust, and knowledge sharing. The findings also demonstrated that organizational trust plays a mediating role between perceived organizational support and knowledge sharing.
\end{abstract}

Keywords: Perceived organizational support; Knowledge sharing; Organizational trust; PLS-SEM

Biographical notes: Karim Shateri is an assistant professor of educational management at the Islamic Azad University, Abdanan Center, Abdanan, Iran. $\mathrm{He}$ received his $\mathrm{PhD}$ in the area of educational management from the University of Tehran, Iran. He has published several papers in well-established national and international journals. His research interests focus on organizational behavior, human resource development and teaching and learning in primary and secondary education.

Ali Asghar Hayat is an assistant professor of educational management at the Shiraz University of Medical Sciences, Shiraz, Iran. He received his PhD in the area of educational management from Kharazmi University, Iran. He has published several papers in well-established international journals such as international journal of productivity and quality management, journal of advances in medical education \& professionalism and middle-east journal of 
scientific research. His major teaching and research interests include organizational behavior and management and teaching and learning in higher education especially in medical education.

\section{Introduction}

Knowledge is an unlimited, vital, and invaluable source to organizations that wants to survive in a challenging setting and can be utilized to attain several advantages (Gelard, Boroumand, \& Mohammadi, 2014). Knowledge is considered as a substantial organizational asset to create a competitive advantage; hence, it is imperative to investigate how an organization manages its valuable resources (Bryant, 2003). In healthcare organizations, managers ought to use knowledge management to enhance procedures like creation, application, and sharing of knowledge. In such a way, healthcare organizations will become a learning organization with a maintainable competitive advantage. In other words, it entails how knowledge is acquired, processed, stored, and shared amongst all constituent parts of the organization (Kasim, 2008). Researchers viewed knowledge sharing as one of the essential components of KM (Chiang, Han, \& Chuang, 2011; Muneer, Iqbal, Khan, \& Long, 2014). Researchers have explored various factors that affect individual tendency to exchange knowledge between different organizational settings (de Almeida, Lesca, \& Canton, 2016; Leonardi \& Treem, 2012). Knowledge sharing has substantial consequences in both organizational and individual level like enhancing individual and organizational innovation (Al-Husseini \& Elbeltagi, 2018; Curado, Muñoz-Pascual, \& Galende, 2018), performance (Marouf, 2016), organizational learning (Curado et al., 2018; Park \& Kim, 2018), and individual creativity (Lee, 2018). Notably, in a healthcare setting, knowledge sharing, and management has a significant role in enhancing employee output, and quality of care (Bordoloi \& Islam, 2012), developing new and innovative ideas, services, products, processes, and solutions (Yun, 2013). While knowledge sharing can have several benefits, its shortage can lead to significant medical errors, such as missed diagnosis, malpractice, injury, multidrug interaction, and mortality (Fogarty \& Shaw, 2010).

Sharing knowledge among healthcare practitioners has been recognized as being an essential factor for creating a quality healthcare system (Richardson, Abramson, \& Kaushal, 2012; Adeyelure, Kalema, \& Motlanthe, 2019). Some believe that KS can help organizations to positively impact on their most cherished assets; which is their human resources (Muneer et al., 2014). In the healthcare context, nurses are one of the most critical assets and a primary professional that carry out a crucial role in improving the quality of care. In this regards, lack of adequate knowledge and experience of nurses can lead to poor performance and increase errors (Chang, Huang, Chiang, Hsu, \& Chang, 2012); Hence, to avoid such consequences and to obtain appropriate knowledge, they need to interact with their colleagues and exchange their knowledge and experiences (Chang et al., 2012; Paulin \& Suneson, 2015; Yun, 2013).

Although knowledge sharing can bear many beneficial consequences for the organization, many people are unwilling to interact and share their knowledge. Punniyamoorthy and Asumptha (2019) indicated that academicians are at times reluctant to share knowledge as they consider it their unique selling proposition. Put differently; it can be stated that people are afraid of losing their competitiveness by disseminating their knowledge (Frias-Navarro \& Montoya-Restrepo, 2020). Therefore, it must be accepted that knowledge sharing behavior cannot be achieved easily (Hew \& Hara, 2006). 
According to Yang, van Rijn, and Sanders (2018), two psychological perspectives can be applied to illustrate why employees do not want to disseminate their invaluable knowledge in the workplace. From the cognitive point of view, knowledge frequently remains a personal asset and is not simply stated, which naturally makes it difficult to share. From a motivational perspective, knowledge sharing may give an individual an expert position and usually receive management acclaim, but the shared knowledge typically discloses the secrets that are a distinct competitive advantage, which accordingly weakens the person in a competitive work environment (Yang et al., 2018).

The published research results on the relationship between perceived organizational support and knowledge sharing behavior are incompatible. Put differently; some studies indicate a positive association between these two variables (Bartol, Liu, Zeng, \& Wu, 2009), and others suggest there is no significant relationship between them (Swift \& Virick, 2013). To further understand these inconsistencies, researchers should investigate the potential role of other variables, which are likely to influence the relationship between these two variables. Furthermore, there has been no research conducted in the context of Iranian healthcare organizations that examines the mediating role of organizational trust in the relationship between perceived organizational support and nurses' knowledge sharing so that the present research can bridge this gap. In other words, in this paper, researchers have employed the concept of organizational trust to achieve a more proper understanding of the relationship between perceived organizational support and knowledge sharing, which likely will aid us in explaining the inconsistencies mentioned above.

\subsection{Perceived organizational support and knowledge sharing}

Perceived organizational support is one of the essential factors that researchers have pointed out to affect knowledge sharing behavior (Han, Chiang, \& Yang, 2009). Perceived organizational support represents the extent to which employees believe that their organization values their participation and cares about their well-being (Eisenberger, Fasolo, \& Davis-LaMastro, 1990).

Eisenberger, Huntington, Hutchison, and Sowa (1986), used social exchange theory (Blau, 2017) and the reciprocity norm (Gouldner, 1960) to explain employeeorganization relationships. Employee-organization relationship represents a relationship in which the organization provides its employee benefits and social rewards in exchange for loyalty and work effort (Rhoades \& Eisenberger, 2002). Moreover, there exists a reciprocal relationship between the staff and their organization. According to norms of reciprocity, when employees realize that their organization supports them, they will exhibit desirable work behaviors and extra efforts to accomplish organizational goals (Eisenberger, Armeli, Rexwinkel, Lynch, \& Rhoades, 2001).

Employees are likely to reciprocate the organization's beneficial actions by displaying knowledge-sharing behaviors (Bartol et al., 2009; Eisenberger et al., 1986). One of the ways that employees can contribute to their organization is to share their valuable knowledge with organization staff (Wang \& Noe, 2010). Put differently, employees who receive more support from their organization are more likely to interchange their knowledge and experiences with other employees in the organization. 


\subsection{Perceived organizational support and organizational trust}

Based on Dyer and Chu (2000), trust is gained as a result of assurance that individuals show in their relationship by ignoring their vulnerabilities. Organizational trust is defined as "feeling confidence and support in an employer... organizational trust refers to the belief that an employer will be straightforward and will follow through on commitments" (Gilbert \& Tang, 1998). McAllister (1995), in his classification of organizational trust, referred to cognition and affect-based trust. On the one hand, the trustor's appraisal of the trustee's capabilities and trustworthiness leads to cognition-based trust. On the other hand, affect-based trust produces through emotional bonding between trustor's and trustees, a two-sided care, and concern for one another (McAllister, 1995).

Prior research has suggested a positive relationship between perceived organizational support and organizational trust (Bartol et al., 2009; Dirks \& Ferrin, 2002; Rhoades \& Eisenberger, 2002; Shukla \& Rai, 2015). Celep and Yilmazturk (2012) displayed that organizational trust exerted a significant influence on perceived organizational support. Based on Singh and Malhotra (2015), when people understand the organization supports them, they are more likely to trust their organization. It is noteworthy when individuals are supported by their organization; they will make an affective commitment to the organization (Allen, Shore, \& Griffeth, 2003), which in turn, creates an everlasting trust (Eisenberger et al., 1990). As a result, it can be stated when employees recognize their organization remains their supporter, they are more expected to trust the organization and its members and expose themselves to potential harm.

\subsection{The mediating role of organizational trust in the relationship between perceived organizational support and knowledge sharing}

According to Van Den Hooff and De Ridder (2004), a process in which staff members reciprocally exchange their knowledge and mutually develop new knowledge is referred to as knowledge sharing. The impact of trust has been investigated in many studies on employee behavior (Laschinger, Finegan, \& Shamian, 2001), especially knowledge sharing behavior (Ozlati, 2015; Laschinger et al., 2001). Previous research has shown that trust furthers collaboration and knowledge sharing in the organization (Gillani, Iqbal, Akram, \& Rasheed, 2018; Politis, 2003). In other words, when employees realize the other party is trustworthy, they are more interested in disseminating their valuable knowledge (Parker, Williams, \& Turner, 2006). However, few studies have found that trust does not contribute to knowledge sharing (Chow \& Chan, 2008; Goh \& Sandhu, 2013; Hsu \& Lin, 2008). Furthermore, research has suggested that trust can mediate knowledge sharing and can play as an antecedent to it (Le \& Lei, 2018; Ling, 2011). In general, it can be stated that as long as there is no trust among the employees of the organization, they are reluctant to disseminate their knowledge (Husted \& Michailova, 2002).

\section{Conceptual model}

The current research provides a conceptual model that explores the relationship between perceived organizational support, knowledge sharing, and organizational trust, and the mediating role of organizational trust in the relationship between perceived organizational support and knowledge sharing. The conceptual framework is depicted in Fig. 1. 


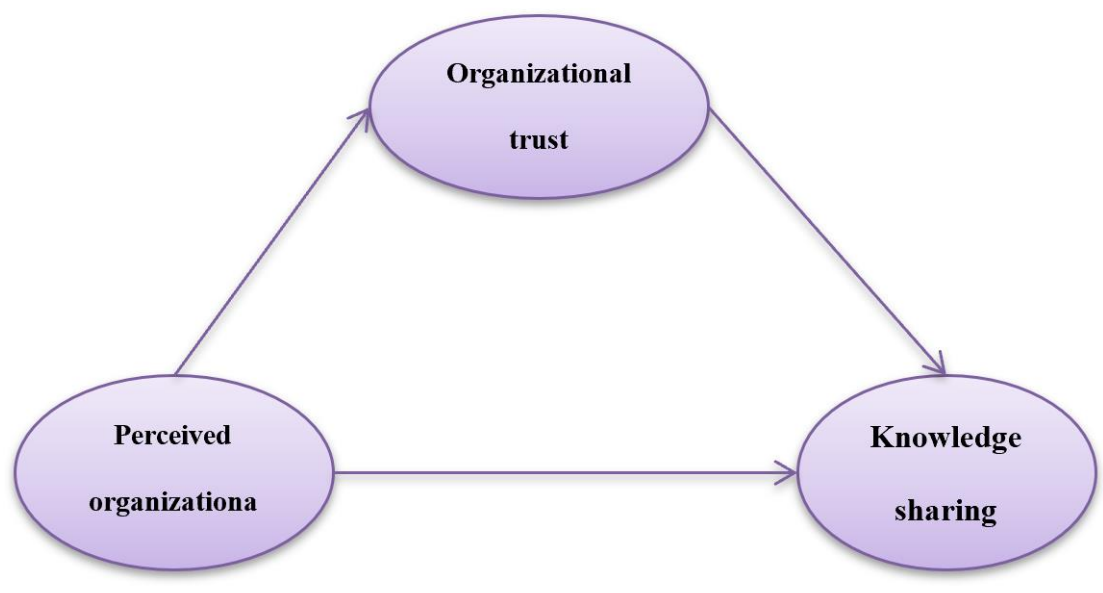

Fig. 1. Proposed research model

According to the research model, the main research hypotheses to be examined in this study are specified as follows:

H1: Perceived organizational support impacts on nurses' knowledge sharing

H2: Perceived organizational support impacts on organizational trust

H3: Organizational trust impacts on nurses' knowledge sharing

H4: Organizational trust mediates the relationship between perceived organizational support and knowledge sharing

\section{Methods}

\subsection{Sample and data collection}

The research conceptual model was tested applying a quantitative cross-sectional research design because of the need to capture information based on data gathered for a specific point in time. The statistical population included all nurses working in five public and teaching hospitals of Shiraz University of Medical Sciences from which 357 nurses were determined as a sample applying Cochran's formulas and considering confidence level of 0.95. In the first stage, a stratified sampling method was employed. After assessing the share of each hospital from the whole sample, the convenience sampling method was applied to select the nurses in each hospital. Self-report questionnaires were utilized to gather required data, and a total of 400 questionnaires were distributed, of which 330 valid prints were completed and returned (Response rates $82.5 \%$.). Participants' demographic information is illustrated in Table 1. Participation was voluntary, and inclusion criteria included nurses working in public and teaching hospitals of Shiraz University of Medical Sciences who had at least two years of work experience and were willing to participate in the research. The participants were assured that the research findings would be maintained private and confidential. 


\subsection{Measures}

Data was collected using three measures. The first measurement was the organizational trust scale adapted from McAllister (1995), consisting of 11 items (McAllister, 1995). The first five items assess affect- based, and the second six items evaluate cognitionbased trust. These items were scored based on a five-point Likert scale from 1(strongly disagree) to 5 (strongly agree). Also, this scale has been extensively utilized in more recent investigations (Ding \& Ng, 2007; Li \& Yan, 2009), and its validity and reliability have been confirmed (Ding \& Ng, 2007; Li \& Yan, 2009). In the current research, reliability estimates using composite reliability for the cognition- and affect-based trust measures were 0.93 and 0.92 . Also, findings showed that the average variance extracted (AVE) of scales was discovered to be 0.68 and 0.69 for affect and cognition-based trust measures, respectively, demonstrating adequate validity.

The second measurement was the knowledge sharing scale designed by Bock, Zmud, Kim, and Lee (2005), consisting of 10 items (34). In this scale, there are two dimensions of attitude toward knowledge sharing, consisting of 5 items and intention to share knowledge involving five items (Bock et al., 2005). These items were scored based on a five-point Likert scale from 1 (strongly disagree) to 5 (strongly agree). Chow and Chan (2008) reported internal consistency reliabilities for each dimension as follows: attitude toward knowledge sharing (0.91) and the intention to share knowledge $(0.89)$ (Chow \& Chan, 2008). In the current research, reliability estimates using composite reliability for the attitude toward knowledge sharing and intention to share knowledge measures were 0.93 and 0.95 . Moreover, the average variance extracted (AVE) was found to be 0.71 and 0.78 for attitude toward knowledge sharing and intention to share knowledge respectively, which indicate the appropriateness of scales' validity (Table 3).

The third measurement was the perceived organizational support scale designed by Eisenberger et al. (1986). They developed a 36-item scale to measure perceived organizational support. According to Rhoades and Eisenberger (2002), since the original scale is one-dimensional and maintains high internal reliability, there are no problems to employ shorter versions of this scale. Therefore, in subsequent investigations, the scale was shortened to 8 items, and only the questions that had the highest factor loading were chosen. However, research advocates that a shorter version is more effective than a longer one (Worley, Fuqua, \& Hellman, 2009). This scale was measured on a 5-point Likert scale from 1 (strongly disagree) to 5 (strongly agree). The reliability and validity of this tool have been confirmed in various studies (Eisenberger, Rhoades, \& Cameron, 1999; Kraimer, Wayne, \& Jaworski, 2001). In the present research, reliability estimates using composite reliability for the perceived organizational support measure was 0.97 . Further, the scale's validity has found to be 0.79 , applying average variance extracted (AVE), indicating the appropriate validity of this scale (Table 3 ).

\subsection{Data analysis}

The data were analyzed applying SPSS version 22 and Smart-PLS version 3.0. To test the reliability and validity and to analyze the multiple relationships between the variables, Structural Equation Modeling (SEM) with Partial Least Squares (PLS) approach was applied. Concerning the analysis, PLS-SEM is a two-stage procedure, including the evaluation of the measurement and the structural model (Anderson \& Gerbing, 1988). Based on Becker, Klein, and Wetzels (2012) it can be stated that regarding trust and knowledge sharing, researchers have used a hierarchical latent variable model which consisted of a reflective-reflective second-order model with a two-stage approach. 
Regarding perceived organizational support, we have used the first-order construct in Smart PLS.

\section{Results}

The participants' demographic information is outlined in Table 1.

Table 1

Participants' demographic information

\begin{tabular}{lccc}
\hline & & Frequency & Percentage \\
\hline \multirow{2}{*}{ Gender } & Female & 293 & $88.8 \%$ \\
& Male & 37 & $11.2 \%$ \\
\multirow{3}{*}{ Age } & $20-30$ & 71 & $21.5 \%$ \\
& $31-40$ & 153 & $46.3 \%$ \\
\multirow{3}{*}{ Work experience } & $41-50$ & 92 & $27.8 \%$ \\
& More than 50 & 14 & $4.2 \%$ \\
& less than 11 & 107 & $32.4 \%$ \\
& $11-20$ & 172 & $52.1 \%$ \\
& More than 20 & 51 & $15.4 \%$ \\
\hline
\end{tabular}

\subsection{Measurement model}

Discriminant validity, convergent validity, and internal consistency reliability were evaluated in this section. The composite reliability (CR) was applied to measure internal consistency reliability. The CR is acceptable at $\geq 0.7$ (Fornell \& Larcker, 1981). The results indicated all constructs' CR scores were above the recommended criterion of 0.7 , demonstrating the appropriateness of the scales. Next, to determine the convergent validity of constructs, factor loadings, and average variance extracted (AVE) were assessed. If all item loadings are greater than 0.7, they can be considered appropriate (Fornell \& Larcker, 1981). According to the findings of the measurement model (Table 3 ), all items indicated a loading higher than 0.7 on their corresponding construct with appropriate AVE ranging from 0.68 to 0.79 . Findings also showed a suitable discriminant validity as all the square roots of AVE were larger than the inter-construct correlations (Table 2). Therefore, the reliability and validity of the research constructs were achieved.

Table 2

Discriminated validity of research constructs

\begin{tabular}{lccc}
\hline Construct & $\begin{array}{c}\text { Knowledge } \\
\text { sharing (ks) }\end{array}$ & $\begin{array}{c}\text { Perceived organizational } \\
\text { support (os) }\end{array}$ & $\begin{array}{c}\text { Organizational } \\
\text { trust (ot) }\end{array}$ \\
\hline $\begin{array}{l}\text { Knowledge sharing (ks) } \\
\text { Perceived organizational }\end{array}$ & 0.96 & & \\
$\begin{array}{l}\text { support (os) } \\
\text { Organizational trust (ot) }\end{array}$ & 0.35 & 0.89 & 0.921 \\
\hline
\end{tabular}


Table 3

Factor loadings, CR, and AVE $(\mathrm{n}=330)$

\begin{tabular}{|c|c|c|c|c|c|}
\hline Construct & Items & Loadings & CR & AVE & $\begin{array}{c}\text { Convergent } \\
\text { Validity }\end{array}$ \\
\hline \multirow{8}{*}{$\begin{array}{l}\text { Perceived } \\
\text { organizational } \\
\text { support (os) }\end{array}$} & os1 & 0.93 & \multirow[t]{8}{*}{0.97} & \multirow[t]{8}{*}{0.79} & \multirow[t]{8}{*}{ Yes } \\
\hline & os 2 & 0.87 & & & \\
\hline & os 3 & 0.91 & & & \\
\hline & os 4 & 0.92 & & & \\
\hline & os 5 & 0.84 & & & \\
\hline & os6 & 0.88 & & & \\
\hline & os7 & 0.87 & & & \\
\hline & os 8 & 0.87 & & & \\
\hline \multirow{5}{*}{$\begin{array}{l}\text { Affect- based } \\
\text { trust (ot) }\end{array}$} & ot1 & 0.79 & \multirow[t]{5}{*}{0.92} & \multirow[t]{5}{*}{0.68} & \multirow[t]{5}{*}{ Yes } \\
\hline & ot 2 & 0.91 & & & \\
\hline & ot3 & 0.81 & & & \\
\hline & ot 4 & 0.78 & & & \\
\hline & ot5 & 0.85 & & & \\
\hline \multirow{6}{*}{$\begin{array}{l}\text { Cognition-based } \\
\text { trust (ot) }\end{array}$} & ot6 & 0.80 & \multirow[t]{6}{*}{0.93} & \multirow[t]{6}{*}{0.69} & \multirow[t]{6}{*}{ Yes } \\
\hline & ot7 & 0.87 & & & \\
\hline & ot8 & 0.84 & & & \\
\hline & ot 9 & 0.82 & & & \\
\hline & ot10 & 0.84 & & & \\
\hline & ot11 & 0.82 & & & \\
\hline \multirow{5}{*}{$\begin{array}{l}\text { Attitude toward } \\
\text { knowledge } \\
\text { sharing (ks) }\end{array}$} & ks 1 & 0.80 & \multirow[t]{5}{*}{0.93} & \multirow[t]{5}{*}{0.71} & \multirow[t]{5}{*}{ Yes } \\
\hline & ks2 & 0.90 & & & \\
\hline & ks3 & 0.88 & & & \\
\hline & ks4 & 0.75 & & & \\
\hline & ks5 & 0.86 & & & \\
\hline \multirow{5}{*}{$\begin{array}{l}\text { Intention to share } \\
\text { knowledge (ks) }\end{array}$} & ks6 & 0.84 & \multirow[t]{5}{*}{0.95} & \multirow[t]{5}{*}{0.78} & \multirow[t]{5}{*}{ Yes } \\
\hline & ks7 & 0.93 & & & \\
\hline & ks8 & 0.89 & & & \\
\hline & ks9 & 0.89 & & & \\
\hline & ks10 & 0.94 & & & \\
\hline
\end{tabular}

\subsection{Structural model}

The hypothesized relationships in the proposed conceptual model were assessed applying structural model assessment. The path coefficients $(\beta)$ and the coefficient of determination $\left(R^{2}\right)$ represent parameters to specifically support the conceptual model and hypothesized relations (Hair, Hult, Ringle, \& Sarstedt, 2016). Also, PLS path-analysis of bootstrapping was applied to understand whether the path coefficients of hypothesized relationships are significant or not. 
The estimated path coefficients are indicated in Fig. 2. According to the obtained results, all research hypotheses were approved (Table 4). As shown in Fig. 3, To specify the significance of the assumed relationships in the conceptual model, the bootstrap procedure was applied (Henseler, Ringle, \& Sarstedt, 2015). Perceived organizational support exerted a direct, positive and statistically significant impact on knowledge sharing based on the t-test statistics (H1 $p<0.001)$ and as it was hypothesized, on organizational trust $(\mathrm{H} 2 p<0.001)$. Similarly, organizational trust exerted a direct, positive, and statistically significant influence on knowledge sharing ( $\mathrm{H} 3 p<0.001)$. Moreover, the mediation test indicated the perceived organizational support indirectly affected knowledge sharing through organizational trust (H4) $(b=0.129, t=3.60, p<$ $0.001)$.

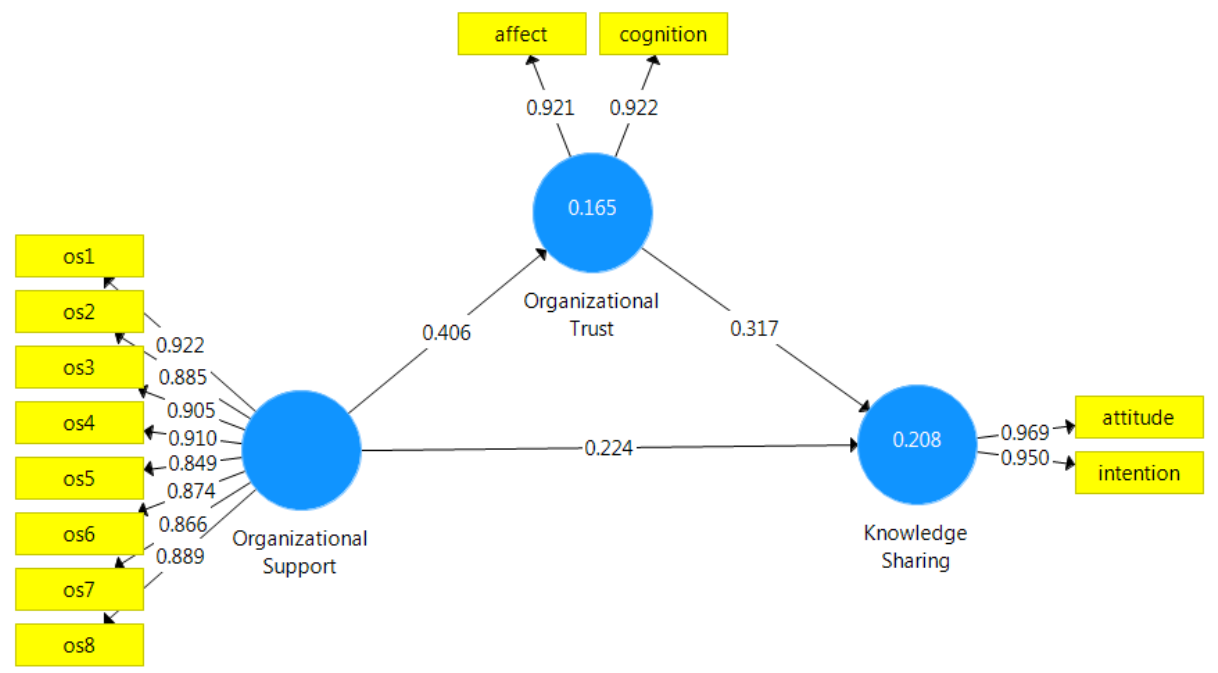

Fig. 2. PLS-path analysis

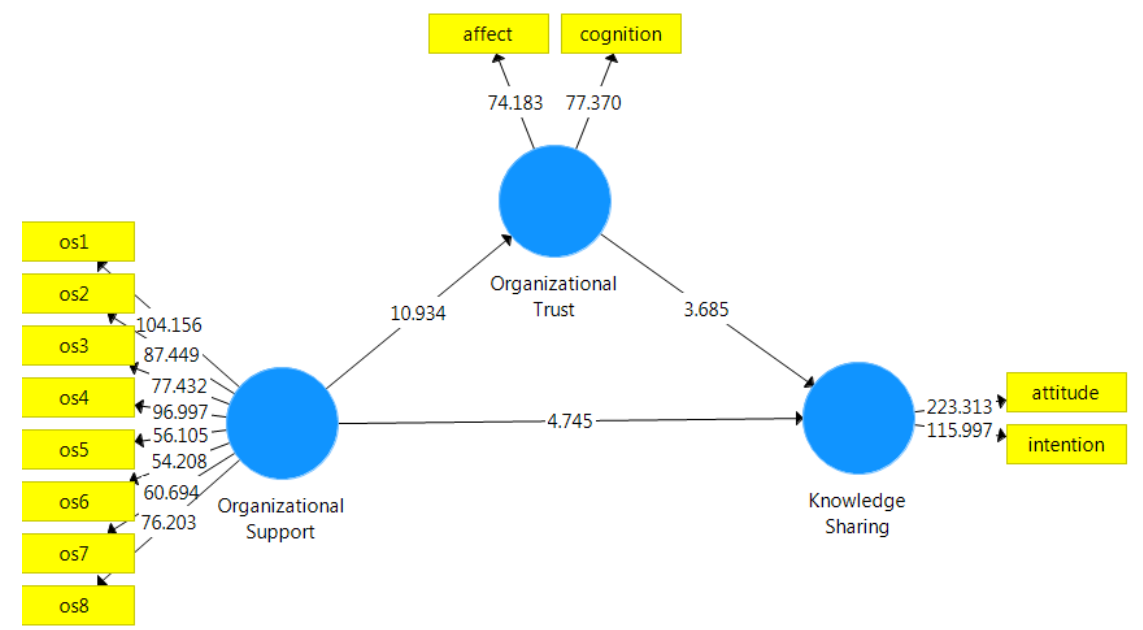

Fig. 3. PLS-path analysis of bootstrapping 
The goodness-of-fit $R^{2}$ of the latent endogenous variables can be utilized to assess the utility of the proposed model. Findings showed that perceived organizational support and organizational trust could explain $20.8 \%$ of the variance in knowledge sharing. Moreover, results indicated that perceived organizational support could explain $16.5 \%$ of the variance in organizational trust. Hair et al. (2016) suggested that researchers report the predictive relevance $(Q 2)$ and effect size $(f 2)$, in addition to basic parameters.

Table 4

Path Coefficients to test hypothesized relationships

\begin{tabular}{|c|c|c|c|c|c|}
\hline Hypotheses & Path & Direct/indirect effects & $\mathrm{T}$ & P. value & Decision \\
\hline $\mathrm{H} 1$ & $\begin{array}{l}\text { Perceived } \\
\text { organizational } \\
\text { support } \rightarrow \\
\text { Knowledge sharing }\end{array}$ & 0.224 & 4.74 & $<0.001$ & Supported \\
\hline $\mathrm{H} 2$ & $\begin{array}{l}\text { Perceived } \\
\text { organizational } \\
\text { support } \rightarrow \\
\text { Organizational trust }\end{array}$ & 0.406 & 10.93 & $<0.001$ & Supported \\
\hline $\mathrm{H} 3$ & $\begin{array}{l}\text { Organizational trust } \\
\rightarrow \\
\text { Knowledge sharing }\end{array}$ & 0.317 & 3.68 & $<0.001$ & Supported \\
\hline $\mathrm{H} 4$ & $\begin{array}{l}\text { Perceived } \\
\text { organizational } \\
\text { support } \\
\rightarrow \\
\stackrel{\text { Organizational trust }}{\rightarrow} \\
\text { Knowledge sharing }\end{array}$ & 0.129 & 3.60 & $<0.001$ & Supported \\
\hline
\end{tabular}

According to Fornell and Cha (1994), the research model holds a predictive relevance when $Q 2$ is larger than zero, whereas a $Q 2$ lesser than zero implies the model has no predictive relevance (Fornell \& Cha, 1994). The results showed the obtained $Q 2$ was discovered to be 0.175 and 0.133 for knowledge sharing and organizational trust, respectively. Chin (1998) stated that $f 2$ values of $0.02,0.15$ and 0.35 , reveal small, medium, and large effects, respectively (Chin, 1998). According to findings, perceived organizational support has a small to medium effect $(0.053)$ on knowledge sharing and medium to substantial effect $(0.20)$ on organizational trust, whereas the influence of organizational trust on knowledge sharing (0.11) was specified as small to medium.

\section{Discussion}

This research investigated the causal relationship between perceived organizational support and nurses' knowledge sharing considering organizational trust as a mediator. Based on the results, perceived organizational support positively and significantly affects nurses' knowledge sharing, which supports the findings of earlier studies (Celep \& Yilmazturk, 2012; Tian, Cai, \& Jiang, 2018). Put differently, staffs who perceive more support from their organizations are more inclined to exhibit knowledge sharing 
behaviors. In other words, when nurses note organizational care and support, they might be eager to disseminate their work experience and valuable knowledge in the hospital. Based on the social exchange theory, we can conclude that individuals tend to reciprocate the organizational support they receive by increasing knowledge sharing behavior, which ultimately will benefit organization. This means, whenever nurses perceive the organizational support, they compensate for it. One way that nurses can compensate for this support is to share their expertise and work experiences with other staff working in the hospital, including colleagues, supervisors, and newcomers.

Furthermore, findings indicated that organizational trust correlates directly with the nurses' knowledge sharing, which supports the results of past researches (Evans, 2012; Ling, 2011; Wang \& Chang, 2015). In this respect, Nonaka believed that trust is an essential foundation to create a shared experience between personnel to assist in knowledge sharing (Nonaka, 1994). As long as there is no trust among the employees of the organization, they are reluctant to share their expertise, skills, and work experiences (Husted \& Michailova, 2002). When nurses trust one another, they are keen on transferring their knowledge and become eager to attain other's knowledge (Moffett, McAdam, \& Parkinson, 2002). In this regard, researchers believe that the trust might influence the readiness of personal to transfer and utilize their knowledge in their colleagues. Therefore, nurses' persuasion to share their knowledge in their organization necessitates the formation of "trust culture," where they become interested in sharing their knowledge without their position being jeopardized. As expected, the climate of trust in an organization has an influential and strong effect, which can act as a significant strength behind sharing knowledge. It can be inferred that people tend to exchange their personal and complex knowledge with their friends. Therefore, we can conclude that nurses with good personal and trustworthy relationships are more likely to contact each other. Consequently, they might have more tendencies to disseminate their experience and expertise. On the other hand, trust can affect the process of sharing knowledge by promoting openness during knowledge exchange to simplify problems. Trust enables knowledge sharing to be readily available at a low cost. And to raise the probability of knowledge gained from colleagues will be adequately comprehensible and absorbable, by allowing the person to put their knowledge in good use. If nurses do not trust each other, the sharing of knowledge will not be accurate, comprehensive, or timely, due to their unwillingness to accept the risks (Ellonen, Blomqvist, \& Puumalainen, 2008).

Furthermore, the results demonstrated that perceived organizational support has a significant and positive association with organizational trust, which supports the previous findings (Dursun, 2015; Kura, Shamsudin, \& Chauhan, 2016). When the staff feels that the organization supports and cares for them, the affective commitment will be produced toward their organization (Allen et al., 2003), that, in turn, provides individuals with a long-term trust in their institution (Eisenberger et al., 1990; Whitener, 2001; Wu, Hsu, \& Yeh, 2007). When nurses realize their hospitals and managers support, their trust will get stronger than before. Creating trust in people through organizational support will ultimately benefit both the organization and the employees because trusting the organization facilitates doing things, and as a catalyst enables the organization's goals to be realized. On the other hand, accomplishing the organizational goals will lead to the attainment of individual goals in the organization. Therefore, serious efforts should be made by managers to constitute a trustworthy environment, which is necessary for any organization.

Moreover, the results indicated that perceived organizational support influences the nurses' knowledge sharing indirectly through the mediating variable of organizational trust that confirms the results of earlier studies (Kura et al., 2016). When perceived 
organizational support significantly correlates with organizational trust, and at the same time, organizational trust is significantly linked to knowledge sharing, it is logically justifiable that organizational trust plays a mediating role in the association between perceived organizational support and knowledge sharing. Based on the social exchange theory, it can be said that when individuals observe more organizational support, they trust the organization more and will try to compensate for the affection of the organization via sharing their knowledge with colleagues and managers in the organization.

\section{Conclusion}

Based on the current research results, organizational support and organizational trust are important predictors of knowledge sharing. Besides, findings showed that organizational trust could mediate the relationship between perceived organizational support and nurses' knowledge sharing. The recognition of organizational trust as a mediator can help Shiraz hospitals' managers to develop appropriate strategies for improving employees' perceived organizational support and organizational trust.

Developing and nurturing knowledge sharing is not merely sending employees to training courses or encouraging them to share their work experiences. It is also about developing an environment where nurses can recognize whether their co-workers are well informed and eager to expand their expertise and knowledge for others to take advantage of it. Some researchers believe the individuals are often terrified of sharing knowledge with others because they think that they will lose their position. Due to this fact, many nurses do not like to take the risk of sharing their knowledge without having a logical reason to trust. Even though trust is established between people, managers can play a prominent role in providing an environment where trust is built and nurtured. Both types of trust can be amplified through direct communication with nurses in collective processes - particularly in circumstances that show interdependency and facilitate an opportunity for nurses to exhibit their competency.

\subsection{Managerial implications}

Overall, for nurses to be successful in their work and provide high-quality health services to patients, they should have enough knowledge and experience. One of the most significant ways that they can obtain these qualities is by sharing knowledge, especially with the newcomers. Senior nurses impart their knowledge with the new staff to improve the quality of nursing care. Also, it is beneficial for patients and the healthcare system.

Considering the impact of organizational trust on knowledge sharing, managers can adopt various measures to develop trust amongst their nurses through arranging various social activities outside the workplace (for example, dining and travelling together). By doing so, we can increase emotional interaction between employees, which brings them closer over time. Consequently, with much lower resistance, they share their useful work experiences in the organization. Engaging nurses in team-oriented tasks or employing them in different parts of the hospital can help to connect them with more peoples and develop more emotional bonds, resulting in sharing their knowledge easier with others.

Generating a mutual understanding regarding organizational goals represent another way that managers can help to develop trust amongst employees. Attention to 
shared values and goals makes employees spend less time and energy on personal motivations and issues.

Ultimately, managers can utilize physical and primarily virtual spaces, where interactions are more comfortable and less costly to increase the interactions between employees. Hence, nurses can generate conversations that lead to trust and share knowledge.

Based on our findings, perceived organizational support performs a critical role in the process of establishing employees' trust. Managers must improve employees understanding of organizational support through practical measures and meeting their expectations and needs.

\subsection{Limitations}

In the current study, researchers made use of questionnaires to gather data; however, selfexpressive data might inevitably include some biases that researchers should consider as limitations. Also, the results of the present research might not represent nurses working in other cities. Therefore, the generalizability of our results might be limited to nurses who work in Shiraz's hospitals. Moreover, according to Schwab, longitudinal data should be used to examine causal relationships (Schwab, 2013). However, the cross-sectional approach used in current research could only explain this phenomenon at a specific time, which could have been expanded to a longitudinal study providing a most profound understanding of casual relationships. Despite the mentioned limitations, we believe our findings can be applied not only to nurses but also to other professions.

\section{Author Statement}

The authors declare that they have no conflict of interest.

\section{Acknowledgements}

The authors would like to thank all nurses for their participation in the survey.

\section{ORCIID}

Karim Shateri (1D https://orcid.org/0000-0002-5202-6777

Ali Asghar Hayat $(\mathbb{D}$ https://orcid.org/0000-0002-4576-8828

\section{References}

Adeyelure, T. S., Kalema, B. M., \& Motlanthe, B. L. (2019). An empirical study of knowledge sharing: A case of the South African healthcare system. Knowledge Management \& E-Learning, 11(1), 114-128.

Al-Husseini, S., \& Elbeltagi, I. (2018). The role of knowledge sharing in enhancing innovation: a comparative study of public and private higher education institutions in Iraq. Innovations in Education and Teaching International, 55(1), 23-33.

Allen, D. G., Shore, L. M., \& Griffeth, R. W. (2003). The role of perceived 
organizational support and supportive human resource practices in the turnover process. Journal of Management, 29(1), 99-118.

Anderson, J. C., \& Gerbing, D. W. (1988). Structural equation modeling in practice: A review and recommended two-step approach. Psychological Bulletin, 103(3), 411423

Bartol, K. M., Liu, W., Zeng, X., \& Wu, K. (2009). Social exchange and knowledge sharing among knowledge workers: The moderating role of perceived job security. Management and Organization Review, 5(2), 223-240.

Becker, J.-M., Klein, K., \& Wetzels, M. (2012). Hierarchical latent variable models in PLS-SEM: Guidelines for using reflective-formative type models. Long Range Planning, 45(5/6), 359-394.

Blau, P. M. (2017). Exchange and power in social life. New York, NY: Routledge.

Bock, G.-W., Zmud, R. W., Kim, Y.-G., \& Lee, J.-N. (2005). Behavioral intention formation in knowledge sharing: Examining the roles of extrinsic motivators, socialpsychological forces, and organizational climate. MIS Quarterly, 29(1), 87-111.

Bordoloi, P., \& Islam, N. (2012). Knowledge management practices and healthcare delivery: a contingency framework. The Electronic Journal of Knowledge Management, 10(2), 110-120.

Bryant, S. E. (2003). The role of transformational and transactional leadership in creating, sharing and exploiting organizational knowledge. Journal of Leadership \& Organizational Studies, 9(4), 32-44.

Celep, C., \& Yilmazturk, O. E. (2012). The relationship among organizational trust, multidimensional organizational commitment and perceived organizational support in educational organizations. Procedia-Social and Behavioral Sciences, 46, 5763-5776.

Chang, C. W., Huang, H. C., Chiang, C. Y., Hsu, C. P., \& Chang, C. C. (2012). Social capital and knowledge sharing: Effects on patient safety. Journal of Advanced Nursing, 68(8), 1793-1803.

Chiang, H.-H., Han, T.-S., \& Chuang, J.-S. (2011). The relationship between highcommitment HRM and knowledge-sharing behavior and its mediators. International Journal of Manpower, 32(5/6), 604-622.

Chin, W. W. (1998). The partial least squares approach to structural equation modeling. In G. A. Marcoulides (Ed.), Modern methods for business research (pp. 295-336). Mahwah, NJ: Lawrence Erlbaum Associates.

Chow, W. S., \& Chan, L. S. (2008). Social network, social trust and shared goals in organizational knowledge sharing. Information \& Management, 45(7), 458-465.

Curado, C., Muñoz-Pascual, L., \& Galende, J. (2018). Antecedents to innovation performance in SMEs: A mixed-methods approach. Journal of Business Research, 89, 206-215.

de Almeida, F. C., Lesca, H., \& Canton, A. W. P. (2016). Intrinsic motivation for knowledge sharing-competitive intelligence process in a telecom company. Journal of Knowledge Management, 20(6), 1282-1301.

Ding, Z., \& Ng, F. (2007). Reliability and validity of the Chinese version of McAllister's trust scale. Construction Management and Economics, 25(11), 1107-1117.

Dirks, K. T., \& Ferrin, D. L. (2002). Trust in leadership: Meta-analytic findings and implications for research and practice. Journal of Applied Psychology, 87(4), 611-628.

Dursun, E. (2015). The relation between organizational trust, organizational support and organizational commitment. African Journal of Business Management, 9(4), 134-156.

Dyer, J. H., \& Chu, W. (2000). The determinants of trust in supplier-automaker relationships in the U.S., Japan and Korea. Journal of International Business Studies, 31(2), 259-285.

Eisenberger, R., Armeli, S., Rexwinkel, B., Lynch, P. D., \& Rhoades, L. (2001). 
Reciprocation of perceived organizational support. Journal of Applied Psychology, 86(1), 42-51.

Eisenberger, R., Fasolo, P., \& Davis-LaMastro, V. (1990). Perceived organizational support and employee diligence, commitment, and innovation. Journal of Applied Psychology, 75(1), 51-59.

Eisenberger, R., Huntington, R., Hutchison, S., \& Sowa, D. (1986). Perceived organizational support. Journal of Applied Psychology, 71(3), 500-507.

Eisenberger, R., Rhoades, L., \& Cameron, J. (1999). Does pay for performance increase or decrease perceived self-determination and intrinsic motivation? Journal of Personality and Social Psychology, 77(5), 1026-1040.

Ellonen, R., Blomqvist, K., \& Puumalainen, K. (2008). The role of trust in organisational innovativeness. European Journal of Innovation Management, 11(2), 160-181.

Evans, M. M. (2012). Knowledge sharing: An empirical study of the role of trust and other social-cognitive factors in an organizational setting. Doctoral dissertation, University of Toronto, Canada.

Fogarty, G. J., \& Shaw, A. (2010). Safety climate and the theory of planned behavior: Towards the prediction of unsafe behavior. Accident Analysis \& Prevention, 42(5), $1455-1459$.

Fornell, C., \& Cha, J. (1994). Partial least squares. In R. Bagozzi (Ed.), Advanced methods of marketing research (pp. 52-78). Oxford, UK: Blackwell Publishers.

Fornell, C., \& Larcker, D. F. (1981). Evaluating structural equation models with unobservable variables and measurement error. Journal of Marketing Research, 18(1), 39-50.

Frias-Navarro, R., \& Montoya-Restrepo, L. A. (2020). Understanding knowledge creation processes among rural communities in post-conflict settings in Colombia. Knowledge Management \& E-Learning, 12(2), 231-255.

Gelard, P., Boroumand, Z., \& Mohammadi, A. (2014). Relationship between transformational leadership and knowledge management. International Journal of Information Science and Management (IJISM), 12(2), 67-82.

Gilbert, J. A., \& Tang, T. L.-P. (1998). An examination of organizational trust antecedents. Public Personnel Management, 27(3), 321-338.

Gillani, S. M. F., Iqbal, S., Akram, S., \& Rasheed, M. (2018). Specific antecedents of employees' knowledge sharing behavior. VINE Journal of Information and Knowledge Management Systems, 48(2), 178-198.

Goh, S. K., \& Sandhu, M. S. (2013). Knowledge sharing among Malaysian academics: Influence of affective commitment and trust. Electronic Journal of Knowledge Management, 11(1), 38-48.

Gouldner, A. W. (1960). The norm of reciprocity: A preliminary statement. American Sociological Review, 25(2), 161-178.

Hair Jr, J. F., Hult, G. T. M., Ringle, C., \& Sarstedt, M. (2016). A primer on partial least squares structural equation modeling (PLS-SEM). Sage Publications.

Han, T.-S., Chiang, H.-H., \& Yang, T.-C. (2009). High commitment HRM, perceived organizational support, trust, and knowledge sharing: A multiple-level analysis. Management Review, 28(1), 25-44.

Henseler, J., Ringle, C. M., \& Sarstedt, M. (2015). A new criterion for assessing discriminant validity in variance-based structural equation modeling. Journal of the Academy of Marketing Science, 43(1), 115-135.

Hew, K. F., \& Hara, N. (2006). Identifying factors that encourage and hinder knowledge sharing in a longstanding online community of practice. Journal of Interactive Online Learning, 5(3), 297-316.

Hsu, C.-L., \& Lin, J. C.-C. (2008). Acceptance of blog usage: The roles of technology acceptance, social influence and knowledge sharing motivation. Information \& 
management, 45(1), 65-74.

Husted, K., \& Michailova, S. (2002). Diagnosing and fighting knowledge-sharing hostility. Organizational Dynamics, 31(1), 60-73.

Kasim, R. S. R. (2008). The relationship of knowledge management practices, competencies and the organizational performance of government departments in Malaysia. International Journal of Social and Human Sciences, 2(12), 740-746.

Kraimer, M. L., Wayne, S. J., \& Jaworski, R. A. A. (2001). Sources of support and expatriate performance: The mediating role of expatriate adjustment. Personnel Psychology, 54(1), 71-99.

Kura, K. M., Shamsudin, F. M., \& Chauhan, A. (2016). Organisational trust as a mediator between perceived organisational support and constructive deviance. International Journal of Business and Society, 17(1), 1-18.

Laschinger, H. K. S., Finegan, J., \& Shamian, J. (2001). The impact of workplace empowerment, organizational trust on staff nurses' work satisfaction and organizational commitment. Health Care Management Review, 26(3), 7-23.

Le, P. B., \& Lei, H. (2018). The mediating role of trust in stimulating the relationship between transformational leadership and knowledge sharing processes. Journal of Knowledge Management, 22(3), 521-537.

Lee, J. (2018). The effects of knowledge sharing on individual creativity in higher education institutions: Socio-technical view. Administrative Sciences, 8(2): 21.

Leonardi, P. M., \& Treem, J. W. (2012). Knowledge management technology as a stage for strategic self-presentation: Implications for knowledge sharing in organizations. Information and Organization, 22(1), 37-59.

Li, N., \& Yan, J. (2009). The effects of trust climate on individual performance. Frontiers of Business Research in China, 3(1), 27-49.

Ling, C. T. N. (2011). Culture and trust in fostering knowledge-sharing. Electronic Journal of Knowledge Management, 9(4), 328-339.

Marouf, L. (2016). The role of knowledge sharing culture in business performance. VINE Journal of Information and Knowledge Management Systems, 46(2), 154-174.

McAllister, D. J. (1995). Affect-and cognition-based trust as foundations for interpersonal cooperation in organizations. Academy of Management Journal, 38(1), 24-59.

Moffett, S., McAdam, R., \& Parkinson, S. (2002). Developing a model for technology and cultural factors in knowledge management: A factor analysis. Knowledge and Process Management, 9(4), 237-255.

Muneer, S., Iqbal, S. M. J., Khan, S. U. R., \& Long, C. S. (2014). An incorporated structure of perceived organizational support, knowledge-sharing behavior, organizational trust and organizational commitment: A strategic knowledge management approach. Pakistan Journal of Commerce \& Social Sciences, 8(1), 4257.

Nonaka, I. (1994). A dynamic theory of organizational knowledge creation. Organization Science, 5(1), 14-37.

Ozlati, S. (2015). The moderating effect of trust on the relationship between autonomy and knowledge sharing: A national multi-industry survey of knowledge workers. Knowledge and Process Management, 22(3), 191-205.

Park, S., \& Kim, E.-J. (2018). Fostering organizational learning through leadership and knowledge sharing. Journal of Knowledge Management, 22(6), 1408-1423

Parker, S. K., Williams, H. M., \& Turner, N. (2006). Modeling the antecedents of proactive behavior at work. Journal of Applied Psychology, 91(3), 636-652.

Paulin, D., \& Suneson, K. (2015). Knowledge transfer, knowledge sharing and knowledge barriers-three blurry terms in KM. In K. A. Grant \& J Dumay (Eds.), 
Leading Issues in Knowledge Management (vol. 2, pp. 73-94). Academic Conferences and Publishing International Limited.

Politis, J. D. (2003). The connection between trust and knowledge management: What are its implications for team performance. Journal of Knowledge Management, 7(5), 5566.

Punniyamoorthy, M., \& Asumptha, J. A. (2019). A study on knowledge sharing behavior among academicians in India. Knowledge Management \& E-Learning, 11(1), 95-113.

Rhoades, L., \& Eisenberger, R. (2002). Perceived organizational support: A review of the literature. Journal of Applied Psychology, 87(4), 698-714.

Richardson, J. E., Abramson, E. L., \& Kaushal, R. (2012). The value of health information exchange. Journal of Healthcare Leadership, 4, 17-23.

Schwab, D. P. (2013). Research methods for organizational studies. Psychology Press.

Shukla, A., \& Rai, H. (2015). Linking perceived organizational support to organizational trust and commitment: moderating role of psychological capital. Global Business Review, 16(6), 981-996.

Singh, B. S. P., \& Malhotra, M. (2015). The mediating role of trust in the relationship between perceived organizational support and silence. International Journal of Scientific and Research Publications, 5(9): 3.

Swift, M. L., \& Virick, M. (2013). Perceived support, knowledge tacitness, and provider knowledge sharing. Group \& Organization Management, 38(6), 717-742.

Tian, G., Cai, H., \& Jiang, Y. (2018). A study of the effects of organizational support on organizational learning based on knowledge management. Eurasia Journal Mathematics, Science Technology Education, 14(5), 1979-1986.

Van Den Hooff, B., \& De Ridder, J. A. (2004). Knowledge sharing in context: The influence of organizational commitment, communication climate and CMC use on knowledge sharing. Journal of Knowledge Management, 8(6), 117-130.

Wang, S., \& Noe, R. A. (2010). Knowledge sharing: A review and directions for future research. Human Resource Management Review, 20(2), 115-131.

Wang, W.-T., \& Chang, W. T. (2015). Antecedents of employees' knowledge sharing intentions: An integrated perspective of interpersonal trust and conflicts. In Proceedings of the 19th Pacific Asia Conference on Information Systems (PACIS).

Whitener, E. M. (2001). Do "high commitment" human resource practices affect employee commitment? A cross-level analysis using hierarchical linear modeling. Journal of Management, 27(5), 515-535.

Worley, J. A., Fuqua, D. R., \& Hellman, C. M. (2009). The survey of perceived organisational support: Which measure should we use? SA Journal of Industrial Psychology, 35(1), 112-116.

Wu, W.-L., Hsu, B.-F., \& Yeh, R.-S. (2007). Fostering the determinants of knowledge transfer: A team-level analysis. Journal of Information Science, 33(3), 326-339.

Yang, H., van Rijn, M. B., \& Sanders, K. (2018). Perceived organizational support and knowledge sharing: Employees' self-construal matters. The International Journal of Human Resource Management. doi: 10.1080/09585192.2018.1443956

Yun, E. K. (2013). Predictors of attitude and intention to use knowledge management system among Korean nurses. Nurse education today, 33(12), 1477-1481. 